\title{
APROXIMACIONES MORFOLÓGICAS EN LA MODELACIÓN DIGITAL EN ARQUITECTURA SISTEMATIZACIÓN DE EXPERIENCIAS CON RELACIÓN AL ESTUDIO DE CRECIMIENTOS Y FRAGMENTACIÓN DE TRAMAS VECTORIALES
}




\section{OMAR CAÑETE ISLAS}

Psicólogo. Magíster en psicología social. Docente en la Escuela de Arquitectura, Universidad de Valparaíso, Chile. Cátedra de Geometría Fractal y Módulo de Forma en Taller de Ciudad. $2^{\circ}$ año carrera de Arquitectura. Autor y coautor de diversos artículos y libros en temas de morfología, estética y ciudad. 


\section{RESUMEN \\ ABSTRACT}

En la presente propuesta se plantean las bases para la ampliación de una exploración hacia nuevos desarrollos morfológicos, como el estudio de gradientes y procesos de fragmentación escalar en la formación de tejidos y paisajes modulares (y no solo crecimiento con módulos de tamaños relativamente fijos usualmente desarrollados). En nuestra propuesta aparecen, como relevantes y complementarias, las nociones de fragmentación y ensamble modular con base en unidades de diverso tamaño y forma, en un marco de asimilación minimalista y esencial.

Junto a lo anterior se muestran modelos y casos generados a partir de la exploración de estos principios aplicados a propuestas desarrolladas por el autor (véase Cañete, 2014; Cañete et al, 2011a, 2011b y 2012), así como por alumnos, con base en encargos del ramo de geometría fractal y en el módulo de forma del taller de ciudad relacionado con el tema de arquitectura vernácula y tejido urbano.

Palabras clave: morfología, crecimiento, fragmentación, tramas modulares, diseño paramétrico, modelación arquitectónica.

In present research, is set bases to open new morphological explorations, such as fragmentation process and gradient, and how they let an organization of textures and modular landscape (and not only modular growing with similar units). It is relevant and complementary notion of fragmentation and modular ensemble supported by unit of different form and grow, in minimal and essential assimilation.

With previous point, we show models and cases generated by exploration of these concepts in workshop generated by author (see Cañete et al, 2011a, 2011b and 2012), and also workshop developed in Fractal Ceometry class and City's workshop.

Key Words: morphology, modular growth, fragmentation, transformational textures, parametric design. 


\section{MARCO TEÓRICO}

[...] la legitimidad del último paso; el abandono del objeto [...] es un tratamiento que altera, simplificando las proporciones de las cosas con respecto a las dimensiones fijadas en la retina [pasando asi] de los datos de la visión transformados primeramente por el sentimiento intuitivo y en seguida por la especulación constructiva.

P. Klee (1971), Teorías del arte moderno (p. 19).

El estudio de morfologías irregulares.

Puntos de confluencia contemporánea

entre ciencia y arte

Desde el punto de la modelación computacional contemporánea, el impacto de las llamadas «teorías de la complejidad» (expresado en geometrías como los fractales) ha revitalizado el estudio de morfologías y transformaciones morfológicas a escala, generando un amplio campo de exploración que podemos denominar como el estudio de las «formas irregulares», asociado a las formas orgánicas y naturales, en contraste con las formas ideales, regulares y abstractas. Como señaló el destacado matemático Benoît Mandelbrot: «La geometría euclidiana es incapaz de descubrir la forma de la nube, una montaña, una costa o un árbol, porque ni las nubes son esféricas, ni las montañas cónicas, ni las costas circulares, ni el tronco de un árbol cilíndrico, ni un rayo viaja en forma rectilínea. Creo que muchas formas de la naturaleza son tan irregulares y fragmentadas que la naturaleza no solo presenta un grado mayor de complejidad, sino que esta se nos revela completamente diferente. La existencia de estas formas representa un desafío: investigación de la morfología de lo amorfo. En respuesta a este desafío, concebí y desarrollé una nueva geometría de la naturaleza y empecé a aplicarla a una serie de campos. Permite describir muchas de las formas irregulares y fragmentadas que nos rodean, dando lugar a teorías coherentes, identificando una serie de formas que llamo fractales. Algunos conjuntos fractales [tienen] formas tan disparatadas que ni en las ciencias ni en las artes he encontrado palabras que los describieran bien» (Mandelbrot, 2000; pp. 9-10).

Esta vinculación emergente entre ciencia y formas naturales ha derivado también en una progresiva disolución de límites en las operaciones entre ciencia y arte, especialmente en el ámbito de la modelación virtual, donde, como señala el destacado filósofo Pablo Oyarzún (2012): «la diferencia epistemológica entre las estrategias de búsqueda en la ciencia y en el arte no es, en modo alguno, irreconciliable». Por cierto, esta apertura y diálogo entre ciencia y arte primordialmente se produce en el campo del estudio de las morfologías, lo que nos hace recordar los planteamientos del propio Kandinsky a inicios del siglo XX, en relación con la importancia que veía en el estudio de las morfologías irregulares naturales para el arte, estableciendo un paralelismo y ámbito de confluencias entre ciencia y arte. Como expresaba Kandinsky: «La aplicación de la línea en la naturaleza es rica y profusa. Solo un investigador, un científico, podría llevar a cabo un estudio sobre este importante tema. Especialmente valioso para el artista sería advertir hasta qué punto el reino independiente de la naturaleza aplica los elementos básicos: qué elementos aparecen, qué propiedades poseen y de qué modo se combinan. Las leyes de com- 
posición de la naturaleza se ofrecen al artista, no para ser imitadas, ya que la naturaleza tiene sus finalidades propias, sino para ser confrontadas con las del arte» (Kandinsky, 1993; pp. 110-111).

Tomando este amplio, dinámico y aún emergente campo es posible indicar diversos momentos en su evolución histórica, donde se configura el desarrollo artístico como teórico, desde el cual pueden articularse ciertos paralelismos entre los principios y enfoques artísticos y científicos. Sí, desde un punto de vista teórico histórico, y abarcando tanto las expresiones pictóricas propias del arte ( $p$. Kandinsky, Moholy-Nagy o Klee) a la matemática y morfologías específicas como los fractales, los sistemas iterados o las teorías del caos (véanse trabajos de Lyndenmayer, Thom, Prigogine o Mandelbrot), es posible afirmar que desde inicios del siglo XX hasta la actualidad se configura un campo de estudio de las denominadas morfologías irregulares, el cual ha pasado por diversas etapas (véase tabla 1).

Sin embargo, en el escenario actual el desarrollo de las artes y estrategias se ve afectado, además, por una doble tensión que en la modernidad y posmodernidad se ha ido consolidando. Por un lado, la constante polisemia e hibridación que fomenta la búsqueda de mecanismos generativos y creativos (poyesis), y por otro lado, la arraigada tendencia a la minimización, optimización funcional y virtualidad de la experiencia cotidiana («menos es más»). En esta condición tensionada, autores como Oyarzún hacen esfuerzos por comprender y acotar la determinación del enigma estético, replanteando la concepción aristotélica de metáfora como «sinapsis de los imposibles». Dice Oyarzún: «La determinación del enig- ma como efecto central de la metáfora que ha tomado la soberanía del discurso es la sinapsis de los imposibles, es decir, de los reales juntamente imposibles, expresadas en la lexis, pero no como coincidencia de las palabras, sino de sus significados, las cosas, evocadas en conjunción por sus símbolos. La sinapsis tiene como agente el desplazamiento (epiphora) metafórico (del género a la especie, de esta al género, de la especie a la especie, o según la analogía), y es, por lo tanto, esencialmente un acontecimiento mental en que es pensada necesariamente la realidad» (2000, p. 129).

Concordantemente con esta «sinapsis de los imposibles», también resultan pertinentes las reflexiones sobre otro concepto, usualmente ubicado en las antípodas de la noción aristotélica: el eidos platónico, el cual ha sido revalorado en torno al debate sobre la generación de copias, modelos y prototipos respecto de una realidad, imagen o idea primera que refleje la contemporaneidad, donde destaca: «el hecho de que toda cosa mundana esté acompañada por su imagen, sino que determina también a las cosas mismas de este mundo, por mucho que ellas sean fieles, similitud mediante, al patrón eidético» (ibídem, p. 234).

Así, el eje de esta reflexión, por un lado, sobre los procesos creativos subyacentes a la formulación artística, bien puede extenderse y aplicarse a la noción de objet trouvé surrealista o incluso duchampiano (asociado al estudio de las instalaciones y el llamado cubismo dinámico) respecto del encuentro subjetivo-objetivo con el azar como fuente del enigma estético antes mencionado, caracterizado por el encuentro generativo existencial permanente del hombre con el azar. 
01-03.

\section{Obra escultórica contemporánea a partir de módulos} morfológicos similares.

El escultor genera tramas paisajísticas a partir de variaciones modulares. La obra está ubicada en el edificio Metlife,

Santiago Centro. Chile.

Autor: Federico Assler, escultor chileno,

Premio Nacional de Arte.

FOTOGRAFÍAS DEL AUTOR

TABLA 1. Cuadro evolutivo-comparativo entre modelos morfológicos y corrientes artísticas contemporáneas

\section{Hitos y modelos del pensamiento complejo}

Constructivismos y formalismos (Piaget, Levy-Strauss, formalistas y constructivistas rusos, estructuralismo) (1910-1950)

Teorías de campo fenomenológico y nociones psicoanalíticas (p.e. asociación libre, inconsciente, sueños, sexualidad, etc.) dinámico-relacionales (no mecanicistas). Teorías de la gestalt y lenguaje de patrones (1920-1950). Cibernética de $1^{\circ}$ y $2^{\circ}$ orden (1950-1980)

Modelos de autómatas celulares, capas y redes neuronales (neural networks) (1980-2000)

Lenguajes computacionales transformacionales añicados al diseño modular (1950-1990) (véase Lindenmayer A. \& Prusinkiewicz, P., 2007)

Estudio de scaling properties fractales al landscape y cartografías (1960-1990) (véase Portschin, Marion; 2007) Estudio de pliegues y estructuras locales que articulan procesos de fragmentación, formación de texturas y gradientes a nivel global (1990-2010) (véase Fodel, 2002; Fuhrer, 2005)

\section{Hitos y corrientes artísticas}

Del cubismo estático (p.e. collage, solapamiento de vistas) y dinámico (Villon, Duchamp) al constructivismo escultórico (Oteiza, Chillida) y al estudio de paradojas, dispositivos e instalaciones (Escher). Surrealismo, dadaísmo, expresionismo.

Pintura abstracta minimalista (Kandinsky, Klee, Mondrian) al Op-art. Del Action Painting al Color Field Painting y la pintura gestural (Pollock, Kline, Guston, Twombly, Rothko, Still, Motherwell, Francis). Del landscape tipo instalaciones paisajísticas (Christo) al landscape computacional (p.e. telemática, Art motion; Whitney, Lippmann, Herbert W. Franke, Vasulka, Gmachl, Koblin, McCabe, Olafur Eliasson, Fischer, Blanz, Pallalink, Marczak, Yoshioka).

De formalismos abstractos y artistas computacionales gráficos (Nees, Mohr, Noll, Götz, Struyken) al arte kinético (Willem van Weeghel, Esnal).

Expresiones perceptuales (dadaísmo, Duchamp, Op-art) al expresionismo abstracto (Matta, Ford).

Del arte concreto (Manessier, Bazaine) e informalismo matérico (Michaux, Burri, Dubuffet, Tapies) al neoexpresionismo y figurativismo primitivista (Barceló, Schnabel).

Fuente: Elaboración propia.

En palabras de Oyarzún: «La postulación surrealista -como se concreta en los objets trouvés- consiste en suprimir el decir de las cosas, cambiarlo por la vigencia material de ellas mismas, su decirse por propia boca, percutidas unas bajo otras» (2000, p. 130). Más aun, el eidos nos abre un siempre amplio marco de reflexión sobre lo virtual y la generación de modelos en el diseño paramétrico computacional contemporáneo. 

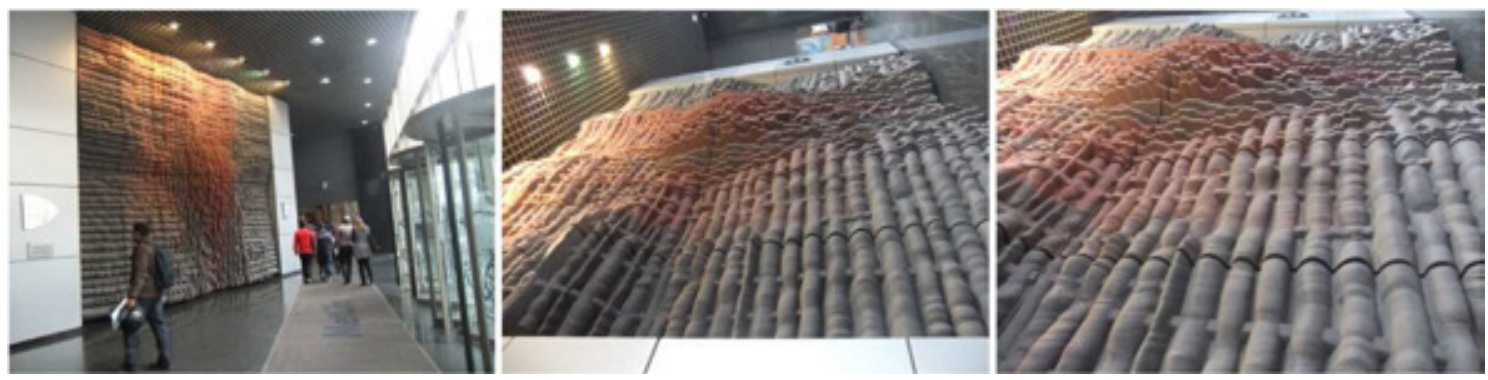

01-03.

Esta supresión y disolución platónica de la realidad en el eidos, sea específicamente en su eidolon o imagen (como lo traduce la tradición latina) en tanto estructura que preserva por un lado la diferencia respecto del objeto-verdad, allende el sujeto, o a través del phantasmata, en tanto espontaneidad que emana y acompaña como eco suprasensorial o mental su presencia (dejando una estela psíquica), ambas aparecen como un marco comprensivo para iniciar una reflexión sobre los procesos creativos asociados a la formulación de modelos ideales mentales o, en nuestro caso, modelos virtuales y su aplicabilidad en el campo proyectual. Como señala Oyarzún: «lo que el artista hace, a través de aquel extraño "producirse" del efecto, no podrá ser jamás considerado como una copia, medida sobre la verdad a despecho de su falta. El dudosísimo producto es denominado por Platón phantasma, "simulacro". Pues precisamente es constitutivo del fantasma aparentar una semejanza que no está, que no se funda en ninguna relación interna con su modelo y, en razón de lo mismo, en ausencia de toda vero-similitud. El fantasma simula la similitud. La similitud simulada del simulacro hace que este, en vez de guardar la distancia simple y respetuosa que guarda la copia-ícono con su modelo, en vez de medirse sobre la verdad, tienda subrepticiamente a suplantarla, a declararla implí- citamente dispensada, a darse como satisfacción de nuestra voluntad, de nuestra necesidad -si la hay- de encuentro con el modelo» (ibídem, p. 230).

En este sentido, la presente propuesta se ha ido desarrollando en una búsqueda por tender puentes, fibras, interconexiones, tejidos e hilos entre diversas dimensiones, depurándolos en una indagación concreta y una propuesta operativa abierta a constantes revisiones y replanteamientos. No obstante, debe tenerse en cuenta que, en nuestro caso, la sinapsis del enigma se hace en la lexis de la morfología y la conjunción del desplazamiento e hibridación espacial tanto virtual como material a través de la generación fantasmática de modelos, asumiendo una concepción del mundo contemporáneo como reflejo de un todo dinámico, interdependiente, híbrido y estructurado simultánea y escalarmente.

Parafraseando a Zubiri (2005, 2006), el proceso creativo supone el contacto de una «realidad relativa» (el hombre) con una realidad que se impone como absoluta en tanto existente y en muchos sentidos inconmensurable («la potencia de lo real en tanto real», en tanto «apertura de lo real en cuanto real»), donde dinámicamente esta realidad existente se difracciona y se depura en la aprehensión sentiente, sea como conjunto o parcialidad de imágenes, fantasías o metáforas, conformando 
esquemas perceptuales-operativos, ${ }^{1}$ y finalmente modelos y eventuales paradigmas, los cuales, en la medida que se ajustan a un cierto rendimiento y coherencia con su realidad fundante, y mantienen vigencia generativa, aparecen como «cercano a la Idea originaria» (nivel fantasmático platónico) para luego develar su dimensión siempre parcial, y por ende de simulacro, y volver al fluir de las ideas entremezcladas con hechos, matriz de la existencia individual y colectiva. En este entrecruce, luego de este momento de contacto existencial (individual y colectivo) con un cierto estado de cosas que aparecen como una «cualidad sin nombre», se abstraen porciones, cualidades, acaso ciertos principios. En este contexto es que hemos discutido el fluir y conformación de la noción de textura como bases de un modelo, al menos operativo en el contexto contemporáneo.

Definido este marco, hemos de comprender a continuación cómo una textura opera como un mecanismo generativo y operativo, aprehendido y potenciado desde su expresión mínima en tanto instancia generadora de paisajes, landscape o conglomerados morfológicos mayores (con propiedades escalares) pero que preserva una organización esencial, además de ser momentos de una transformación e interacción compleja continua.

\footnotetext{
1. Resulta pertinente y complementario el enfoque semiótico de Charles Peirce (véase Pearce, 2010). Al respecto, Deleuze muestra un claro interés por extender lo semiótico al plano visual, espacial y morfológico en conceptos como rizoma, pliegue, lo estriado, las metáforas geológicas en los movimientos de desterritorialización y desestratificación de los sistemas de ideas, entre otras (véase Deleuze, 1984, 1986, 1989 y 2000).
}

\section{Del módulo en transformación a la conformación de texturas, gradientes y landscape}

Si uno compone a base de metáforas [ek metaphoron] habrá enigma [einigma]. Pues la esencia del enigma consiste en unir, diciendo cosas reales, términos inconciliables [ainogmatos te gar idea esti, to legonto hyparkhonta adynata synapsai]. Ahora bien, según la composición de los vocablos no es posible hacer esto, pero si lo es por la metáfora.

Aristóteles, en Poética.

El estudio de texturas en el movimiento moderno, especialmente de corrientes como la Bauhaus, fue abordado inicialmente como una propiedad de las superficies de los materiales, cuya finalidad para el artista solo está dada en la medida de las posibilidades que su uso le permite a través de una biotécnica funcional. Así, inicialmente es asimilada como una mera cualidad asociada al uso y sentido funcional del material de trabajo. La importancia del uso biotécnico se entendía asociada al uso funcional, destacando en instancias tales como el camuflaje, los coloridos ornamentales o el ensamble de capas en fabricaciones artesanales a fin de evitar alabeos o torsiones en la madera u otro material (véase László Moholy-Nagy, 1972). No deja de llamar la atención que pese a la importancia que asigna la Bauhaus en particular (y los formalismos y constructivismos en general) al estudio de los procesos compositivos y constructivos, no haya percibido en la textura un mecanismo generador de superficies, planos y espacios, como en el presente se la concibe y estudia, además de las propiedades anteriores. Posiblemente, el esfuerzo por evitar el problema del ornamento, que solo les permitió valorarla en sus propiedades funcionales en el diseño. Pareciera que el agotamiento del estructuralismo, su disolución en 
la posmodernidad, así como la persistencia de la fenomenología en diversos ámbitos, entre otros «ismos», es lo que configura un campo transversal donde poder valorar lo fragmentado como un ámbito punzante y constitutivo, ${ }^{2}$ aún no aprehendido ni explorado particularmente (véase Arnheim, 2000). Como señala este autor, respecto de la noción de estructura como principio organizativo: «Dado que estos principios son abstractos, se aplican a cualquier tipo de organización. [...] En circunstancias ideales, estas fuerzas constituirían una estructura unificada. En estados menos integrados, el todo puede verse afectado por aberturas en inconsistencias» (p. 18). Por otro lado: «Toda estructura consta de tensiones dirigidas [...]. El equilibrio de todos los vectores apunta a limitar la estructura al mínimo de tensión que puede tolerar. ¡Pero no todos los vectores son constructivos!» (p. 20). Solo progresivamente se toma conciencia de que estos vectores no apuntan siempre en la misma dirección dentro de un sistema, ni todos los principios generales operan en circunstancias siempre ideales. Por esto es que lo fragmentado deja progresivamente de ser una mera constatación de la desilusión posmoderna y empieza a estudiarse en sus cualidades inherentes.

En este nuevo escenario, las propiedades lingüísticogenerativas de las texturas se exploraron inicialmente a partir de, entre otras estrategias, mediante: a) la ruptura del equilibrio en configuraciones perceptuales gestálticas (Arnheim, 2000); b) las configuraciones

2. Resulta pertinente la reflexión de Duchamp (1967) respecto del arte como posible-mordiente: «Posible: La figuración de un posible (no como contrario de imposible ni como relativo a probable, ni como subordinado a verosímil). El posible es solamente un "mordiente" físico (género vitriolo) que hace arder toda estética o calística» (en Cabane, 1967; p. 36). Véase también Oyarzún (2000; p. 262). morfológicas asociadas a un lenguaje computacional de patrones (asociado al estudio de sistemas iterados -véase Lindenmayer, 2007-); o c) ciertas transformaciones asociadas a cualidades escalares propias de procesos de crecimiento o transformación geométrica a escala (véase Mandelbrot, 2000). Es así como estas estrategias han derivado, especialmente en la última década, en un interés por los llamados procesos de fractura de superficies (fractures surfaces), sea en modelos estáticos o dinámico-transformacionales. Como señala Federl (2002): «The existing models of pattern formation can be divided into two classes: models assuming static space and models assuming changing space. Examples of models operating on a static surface are the reaction-diffusion models, originated by Turing in 1952. The generally deal with the distribution dynamics of pattern forming substances in a medium of constant size. L-system models, in contrast, fall into a category of models operating on changing domains. They deal with development, but are limited to branching structures. In spite of the relative success of some models, e.g. reaction-diffusion models that capture shell pigmentation pattern, or L-system models of herbaceous plants, many pattern continue to elude modeling effort. In my research, I explore the hypothesis that some of these patterns can be captured with fracture models operating on growing surfaces, such as bark on tree trunks or drying mud» (Federl, 2005, p. 5).

Por otro lado: «Previous work in the area of simulating fracture formation can be essentially divided into two groups based on the amount of discontinuity produced by fractures in the material. In the first group, the 


\begin{tabular}{|c|c|}
\hline Formas regulares & Formas irregulares \\
\hline Formas cerradas regulares. & Formas abiertas conurbadas o fragmentadas. \\
\hline Geometría euclidea, poliedros (regulares y semirregulares). & $\begin{array}{l}\text { Texturas, gradientes, fractales, landscapes, nodos y grafos, } \\
\text { formas fragmentadas, etc. }\end{array}$ \\
\hline Simetría, centrada en los procesos de cierre y equilibrio. & $\begin{array}{l}\text { Asimetría, centrada en los proceso de tensión y ruptura del } \\
\text { equilibrio. }\end{array}$ \\
\hline Centros únicos y definidos. & Centros múltiples, centroides y no del todo definidos. \\
\hline Generadas mediante ecuaciones lineales. & Generadas mediante ecuaciones no-lineales. \\
\hline Sin propiedades escalares. & Con propiedades escalares. \\
\hline Asociadas a formas acabadas y definidas. & Asociadas a formas inacabadas y en proceso de transformación. \\
\hline
\end{tabular}

Fuente: Elaboración propia.

models use fractures to introduce large discontinuities, i.e, they focus on simulating the process of an object breaking into pieces of applied external forces, with no emphasis on the actual fracture pattern being formed. The second group of models uses fractures to produce small discontinuities in the object's surface, and they focus on the emerging crack pattern. The models in the second group operate either on static or dynamic surfaces» (Federl, 2005; p. 5-6).

Actualmente podemos decir que desde un punto de vista operacional y computacional-gráfico, el estudio de texturas es abordado como:

- Un mecanismo generador de superficies, planos y espacios organizados a escala (fractalmente), como
- Un dispositivo diagramático-paisajístico que organiza y define capas, circulaciones, trayectorias, nodos, redes, detenciones, centros de retroalimentación, inputs y salidas en una trama cambiante.

Así, en este amplio marco que hemos esbozado en el campo de estudio de las formas irregulares, hemos de situarnos en esta última etapa, genéricamente denominada de texturas, en lo que bien podríamos describir como un subcampo que hemos denominado de texturas modulares transformacionales a escala. En este campo delimitaremos algunos principios operacionales específicos, tales como:

- Los procesos de crecimiento y fragmentación interescalar, destacando: 
04

Modelación de primeros procesos de fracturación y formación de texturas con base en L-Systems.

IMAGEN DEL AUTOR

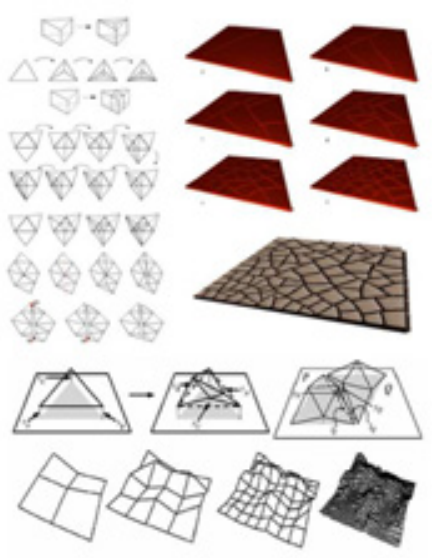

04.

en el procesamiento de datos, la modelación de morfologías se ve potenciada por el salto cibernético-sistémico permitiendo incorporar los procesos de retroalimentación tanto positiva como negativa (iteración de funciones) como mecanismos amplificadores y deformadores de una señal o ruido inicial. Este paso fue decisivo para la conformación de geometrías como los fractales y el estudio de ecuaciones no lineales, al ser incorporadas al bagaje algorítmico, potenciando las nociones de lenguaje y metalenguaje de funciones, actuando como mecanismo modulador en el diseño morfológico (véase Cañete, 2014). Con todo esto se conforman finalmente las bases del actual diseño paramétrico (Shumacher, 2008; 2011).

\section{Morfologías y arte digital}

La cosa no es lo real, sino algo que es como lo real. Con relación al eidos, la cosa -cualquier cosa determinada- es externa, "también oscura en comparación con la realidad» [...]. «He aqui, por fin. La delimitación platónica del arte.»

Pablo Oyarzún, en Anestética del Ready-Made.

En el escenario actual, muchos de los nuevos modos de expresión plástica y estética aparecen asociados no solo al uso de grafismos y morfologías, sino a la mixtura e integración polisémica interdisciplinaria, en confluencia con la asimilación de medios de modelación digital que la contemporaneidad ofrece. De este modo, junto al desarrollo de la computación y el consecuente aceleramiento
El azar del hallazgo se funda en el azar del encuentro. El hallazgo descubre, como encuentro que lo ha precedido interminablemente, un ser-azar que distribuye los entes en sinapsis desde su propia enigmaticidad. $Y$, efectivamente, es en esta zona final donde se abisma la noción irrenunciable del surrealismo, de la cual cree extraer este toda su naturaleza poética.

Pablo Oyarzún, en Anestética del Ready-Made.

Una importante fuente de exploración morfológica de las denominadas formas irregulares se ha dado en el desarrollo de las artes plásticas, en especial del de- 
nominado arte digital computacional gráfico (Cañete, 2014; Cañete y Bahmondes, 2011). Esta tendencia, desde mediados de los años sesenta ha posibilitado que diversos artistas pioneros empezaran a explorar las nuevas herramientas gráfico-computacionales en el ámbito del arte, siendo las primeras exposiciones de autores como Michel Noll, en 1965, marcadas por la evidente influencia, como parte del clima irrepetible de la época, de pintores como Paul Klee, Mondrian (véase Cooper Giloth \& Lynn Pocock-Williams, 2004), los ya clásicos estudios ópticos de Duchamp, los trabajos de Joseph Albers (2010), el Op Art y otros, que son vistos como referentes en esta búsqueda de formas compositivas y minimalistas a la vez, con énfasis en la existencia de patrones puros, simples y esenciales, pero a la vez combinatorios, generativos y transformacionales, que incorporan las nociones de lenguaje formal, propiciadas por el uso de computadores, que inicialmente desarrollado al amparo de la lingüística y la lógica, sentara las bases del cómputo a mediados del siglo XX. Esta metáfora lingüístico-computacional planteada por autores como Noam Chomsky y las teorías psico y sociocibernéticas del observador, en paralelo al desarrollo de la naciente computación (véase Dietrich, F., 2000), o incluso la naciente animación digital y los efectos especiales del cine (véanse Withney, J. 1961, 1971; Youngblood, G., 1970) va a permitir, unas décadas después, en medio de la efervescencia de una época marcada por el inicio de revoluciones y cambios de todo tipo, que de estas y otras confluencias se originen expresiones de una vanguardia plástica conocida como Arte Digital. Sí, aparecen los primeros lenguajes computacionales gráficos, como DOL-Systems (véase
Lindenmeyer \& Przemyslaw, 2004), ASCII, ALGOL o LOGO, los plotters de impresión, y nuevos softwares gráficos diseñados para tales fines, como Blefix, creado por el artista gráfico Kenneth Knowlton en 1964; o Sketch-Pad, de Sutherland, en 1965 (véanse BorjaVillel, Manuel et al; 2005; Dietrich, F., 2000; Lambert, Nick, 2003). Junto a estos pioneros surgen los primeros centros de arte digital gráfico, al amparo de universidades como el MIT, transcurriendo un par de años para las primeras publicaciones hacia 1968.

Con posterioridad a este primer momento en el que predominan el estudio y modelación con base en patrones generativos e iteración de funciones, emerge el diseño y exploración de nuevas morfologías en los años setenta, que abren nuevas posibilidades de exploración mental y morfológica, tales como el estudio de propiedades escalares entre el todo y la parte, así como las dinámicas de crecimiento y la variación e interacción de patrones, el ruido informático, ecuaciones no lineales, procesos estocásticos y azar estadístico, para después, durante los años ochenta y noventa, dar paso a la formación de gradientes, texturas, mallas, tramas, pliegues y landscape, además de hibridaciones y relaciones n-dimensionales, sistemas SIG, nuevas formas cartográficas y las nuevas formas de concebir la experiencia espacial (véase Eliasson, 2010), y la escultura y arte dinámica o en movimiento -Kinetic Art- (véanse Rozin, D. 2010; Weeghel, Willem Van, 2010). Por lo mismo, desde los años sesenta y setenta, al menos en este campo de exploración morfológica, el arte digital ha ido casi de la mano de los avances de la ciencia tecnológica y constituye un referente de estudio y experimentación constante. 


\section{Exploración morfológica \\ y diseño paramétrico}

Estos entes puramente abstractos, y que como tales poseen su vida, su influencia y su fuerza propias, son el cuadrado, el círculo, el triángulo, el rombo, el trapecio y otras innumerables formas, que se hacen cada vez más complejas y pierden su denominación matemática. Todas ellas tienen carta de ciudadanía en el reino abstracto. Entre estos extremos se halla el número infinito de formas, en las que existen ambos elementos y en las que predomina unas veces lo abstracto y otras lo concreto.

Wassily Kandinsky, en Acerca de lo espiritual en el arte.

Desde los inicios y bases del cómputo, planteados por trabajos de pioneros como Alain Turing (véase Hofpstander, 1998) han pasado muchos y vertiginosos desarrollos. Actualmente, lo que propone el diseño paramétrico, por lo tanto, no es la construcción misma del objeto, sino la construcción del sistema que lo compone (véase Shumacher, 2008, 2011). En esta evolución ha habido sin duda avances progresivos relevantes, como el estudio del lenguaje de patrones, la iteración de funciones, los sistemas iterados, lenguajes y metalenguajes computacionales-algorítmicos, diseños modulares, entre otros. Así, las modelaciones morfológicas (p.e. fractales, teoría del caos) progresivamente han introducido mayores grados de regulación y flexibilidad en el diseño paramétrico-generativo (Levitt, 1976; Draves, 2003, 2008; Schumacher, 2008, 2011). A este tipo de retroalimentación del diseño se le llama diseño paramétrico discriminativo (véase Ramírez, G. y Vidal, M., 2000). Actualmente, el diseño mediante uso de algoritmos ha tendido a modelar formas con la confluencia operacional entre múltiples de estas nociones, como modelación de funciones, patrones, y parámetros, donde la forma resultante es regulada por la interacción y variación constante entre estos cálculos, regulados según un fin de diseño.

Así, operaciones morfológicas como la extrusión o la representación espacial de ciertas funciones matemáticas pueden ser combinadas, mediante un meta-algoritmo, con otras operaciones tales como torsiones morfológicas en $3 \mathrm{D}$ de volúmenes o mallas, u operaciones morfológicas de atracción o repulsión ejercida por puntos definidos arbitrariamente desde fuera de la malla de representación. Así, estos puntos ejercen influencia diferencial en los puntos o curvas de nivel que conforman la malla original, ayudando a modelarla «a distancia». Esta malla, a su vez, puede ser el fruto de la libre modelación o de la importación de imágenes vectorizadas originalmente modeladas incluso en otros softwares (véase Draves, 2008). De esta forma la modelación paramétrica ofrece un sinnúmero de posibilidades de diseño y modelación, potenciándose progresivamente mediante nuevos softwares tales como Grasshoper -aplicación de relativa reciente aparición, del conocido software Rhino-, o Autocad, potenciando el diseño digital de los tradicionales módulos constructivos del tradicional diseño modular, como estrategias de ensamblaje modular, etcétera (López, 2012; en Cañete et al, 2012).

\section{Polifonía morfológica. Del objet trouvé a la textura minimalista como objeto morfológico paramétrico}

Desde nuestra óptica, estas exploraciones y óptica sobre la importancia de las texturas permiten una integración polifónico-operativa desde al menos tres frentes. Por un 


\section{TABLA 3. Marco conceptual de trabajo de la presente propuesta}

Encuentro con el azar concebido como instalación o dispositivo como fuente del enigma estético

Surrealismo

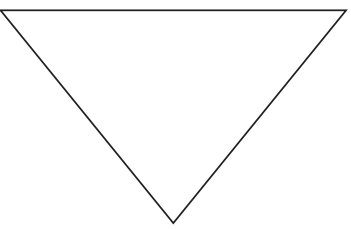

Encuentro con las formas mínimas y esenciales de formas regulares e irregulares como principio estético-compositivo.

Minimalismo pintura abstracta.

Modelación mediante algoritmos y fórmulas.

Diseño paramétrico.

lado, permite replantearnos el problema del objet trouvé surrealista o incluso duchampiano (asociado al estudio de las instalaciones y el llamado cubismo dinámico) respecto del encuentro subjetivo-objetivo con el azar como fuente del enigma estético. Por otro lado, esta concepción se ha de ver enriquecida con el minimalismo propio de la pintura abstracta (véase Cañete, 2012, 2014) y de artistas computacionales gráficos (véase Borja-Villel, Manuel et al, 2005; Dietrich, F., 2000; Lambert, Nick, 2003). En un tercer frente, es el encuentro y devenir de estas influencias históricas con las morfologías virtuales reguladas por operaciones paramétricas lo que genera un marco afín de exploración morfológica de nuestro estudio (véase Shumacher, 2008, 2010).

Este nuevo tipo de operaciones formales nos permite modelar morfologías basadas en procesos compositivos como: a) la discontinuidad y continuidad escalar del trazo; b) la conformación perceptual de líneas y superficies activas como efecto de la vectorización; c) la conformación y gradación transitiva de interioridades y exterioridades morfológicas; d) las relaciones entre corte y forma planar y génesis del vacío en la proyección volumétrica; o e) la relación de tensión y equilibrio dinámico y transformacional entre patrones generativos en la naciente forma. Revisaremos algunos de estos puntos.

a. La tríada: orden lineal-complejidad-azar. La inclusión de formas y relaciones irregulares ha ampliado el horizonte desde el cual se entendía la noción de orden, pasando de una concepción estática y preconcebida a una noción cambiante y generativa. El orden lineal es visto como parte de un continuo, con máximos niveles de completitud, delimitación, inclusión, orden y simetría, que convive con los Ilamados órdenes fuera del equilibrio o por fluctuación, generativos y transformacionales, propio de las teorías de la complejidad.

En este segundo tipo de relaciones de orden predominan simetrías a escala parciales y cambiantes, con una gama de gradientes, texturas, propia de las variaciones escalares, como los fractales, los pliegues, bifurcaciones, catástrofes thomianas, conurbaciones y teorías del caos. De este segundo nivel de orden complejo pasamos al plano de las asociaciones y variaciones es- 
tocásticas, que tienden a la dispersión tanto temporal como espacial de cualquier sistema, donde la repetición discontinua de patrones o proporciones es el modo más estable de armonía o simetría (más propia de los niveles anteriores). En este marco el azar aparece como límite más cercano a la desintegración sistémica, propia del desorden y la negentropía. En este nuevo enfoque comprensivo no es de extrañar que nociones como las de vibración aparezcan como marco para comprender el paso continuo de un tipo de organización u orden a otro (Cañete, 2012).

\section{b. Los procesos de crecimiento y fragmentación mor-} fológica como mecanismos generadores de tramas. Como se ha visto, ya en los años cincuenta empiezan a estudiarse los procesos de formación de tejidos y tramas, pero siempre en relación con los procesos de crecimiento, entendidos como un agregado funcional de unidades o módulos relativamente similares en un espacio o intersticios. Sin embargo, desde fines de los años noventa empiezan a introducirse nociones de variabilidad a escala en la modelación morfológica (y no solo la similitud escalar), llevando a relevar la importancia de los procesos de fractura y fragmentación formal como modelos de trabajo en la modelación morfológica.

\section{c. Continuidad mínima esencial del trazo y línea mor-} fológica fractal. Esta dimensión será modelada mediante técnicas de vectorización de imágenes (en softwares como Corel Draw-5) de morfologías y fórmulas fractales inicialmente generadas en softwares como Fractint y Apohisys, lo que resulta en líneas fragmentadas que se ramifican, conurban y escalan en unidades morfológicas, manteniendo una coherencia compositiva global a partir del mismo trazo esencial minimalista de la imagen inicial, recordándonos a la vez las infinitas posibilidades y modos en que una línea puede pasar y unir dos y más puntos. Operacionalmente, un vector no trabaja con base en la reproducción de un mapa de puntos, sino en el trazado de múltiples líneas entre puntos. Esto permite modelar morfologías variando parámetros como el número de nodos y líneas que abarcara el máximo de puntos en la imagen en tanto mapa de bit original.

\section{d. El estudio de texturas como formas transicionales} en la mixtura y variación morfológica del trazo, generadora de landscape. ${ }^{3}$ Las líneas fractales que se conurban y ramifican a escala, en procesos de fragmentación y formación de gradientes, permiten el surgimiento de interacciones continuas con la forma y el entorno, a través de proporciones y tensiones entre planos y formas, alternando entre tramas compositivas regulares e irregulares. Lo anterior permite explorar compositivamente la mixtura y variaciones morfológicas desde la continuidad de la conurbación de la línea o trazo fragmentado. Las formas así creadas permiten explorar tramas y figuras que, oscilando entre puntos de mayor o menor apertura o cierre gestáltico, van multiplicando, variando y alternando espacios de mayor o menor interioridad o exterioridad a la vez. El conjunto de esta evolución es una fuente generadora de landscape.

\footnotetext{
3. En psicoanálisis, Winnicot (1959) plantea la noción de objeto transicional, definido como un momento psíquico, en un continuo o transición entre muchos planos y pasajes mentales, que transita entre la interioridad subjetiva regida por el principio de placer, y la exterioridad por el principio de realidad objetiva.
} 
Por último, debemos señalar también que estas características permiten replantearnos la clásica distinción entre formas regulares, ideales y la riquísima y aún poco explorada gama de formas y relaciones irregulares.

Importancia de la forma en las corrientes contemporáneas. El estudio de tramas, texturas, tejidos y gradientes morfológicas en arquitectura

Vamos a hablar asimismo de los laberintos, que son las obras más prodigiosas del ingenio humano, y cuya existencia no es, como puede creerse, una mera invención.

Plinio el Viejo, en Textos de historia del arte.

El estudio de la arquitectura siempre ha sido sensible y ha buscado asimilar el estudio morfológico y las posibilidades que ofrece desde el punto de vista proyectual, intentando vincular y estrechar los campos estéticos a los de habitabilidad cotidiana.

En el caso de las formas irregulares en la arquitectura moderna (en paralelo a los estudios sobre ciudad vernácula y lenguaje de patrones de Alexander), un primer momento aparece con posterioridad al concepto de «planta libre» desarrollado por Le Corbusier, la Bauhaus y finalmente Mies, y de modo paralelo las nociones de «líneas puras» y procesos de tensión y equilibrio desarrollados por los constructivistas rusos.
Un segundo momento de relevancia se da con la consolidación del team $X$, basado en una concepción escalar del espacio y tejido urbano, y el interés por los procesos de ruptura de simetría, y cómo los crecimientos modulares permiten intervenciones y proyectos en espacios irregulares usualmente denominados «intersticios» buscando la co-formación de tejidos urbanos y la posterior articulación en una concepción de «ciudad abierta». En los años setenta se pasó a una intensa etapa de exploración morfológica usualmente llamada «arquitectura posmoderna», la cual se caracterizó por la búsqueda formal autónoma, casi escultórica, independiente y ajena a su eventual habitabilidad. Progresivamente, se desarrollan exploraciones intentando la fracturación o quiebre del cubo, o la formación de lo que bien podríamos llamar genéricamente «cuboides» a través de su deformación. Después de los crecimientos modulares se dio paso a la exploración de formas usualmente denominadas de «hipercubo», y finalmente a la exploración, en menor medida, de mallas, layers o capas superpuestas, que desde el punto de vista de la comprensión arquitectónica son las nociones de envolvente y multifuncionalidad, las cuales jugaron el papel articulador y asimilador de estos aportes desde la disciplina.

Será a mediados de los años noventa, luego de introducirse el pliegue como modo nuevo de concebir pro- 
05-08.

Formación de paisajes mínimos.

IMAGEN DEL AUTOR
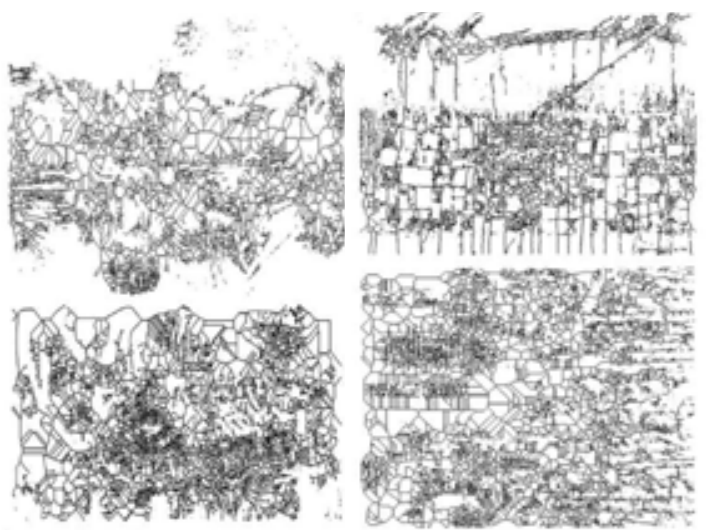

$05-08$.

yectualmente la arquitectura, que se irá depurando la noción de intervenciones con sentido más urbano y menos escultórico. Es así como en el escenario contemporáneo, luego de la irrupción del pliegue, aparece como atractiva la operación de recorte (menos explorada aun) como modo y estrategia globales de abordaje y operación predominante. Es así que podemos replantearnos, respecto de esta nueva valoración que implícitamente se hace, la noción de «líneas puras», que bien podríamos redefinir como «fragmentos, recortes o incisiones puras o depuradas». Así, es posible afirmar que bajo el marco de relevancia y posibilidades que ofrece el estudio de formas y porciones irregulares depuradas se encuadra el desarrollo correlativo de una sensibilidad y una estética que emergen como revisionistas y en algún sentido sintéticas entre las influencias moderna y posmoderna (como la expresada en proyectos como la ampliación del Museo de Girona). Situación similar se da en el estudio de cubiertas y envolventes morfológicas que confluyen hacia un diseño integral, donde la irregularidad de la forma permite integrar, en trazados mínimos y esenciales, diferencias funcionales significativas. Así, el estudio morfológico cumple varias funciones a la vez, y una cubierta puede llegar a ser fachada, plataforma, envolvente, recorrido, deslinde, soporte y revestimiento a la vez. Hasta implícita de la noción de «traslape funcional» (overlaping), originariamente planteado desde el campo de los estudios de ciudades vernaculares (Alexander, 1974, 1979) y, poco a poco, asimilados desde las corrientes posmodernas a fines del siglo pasado en el plano del diseño proyectual. Es así como el estudio de la forma vuelve a estar en vigencia no solo como un elemento de diseño, sino también en relación con sus implicancias en la conformación y articulación de un tejido, así como por su capacidad para generar un sentido urbano, incluso alterno al de las clásicas y en muchos sentidos agotadas nociones de planning master. Lo anterior se puede resumir en el siguiente cuadro resumen (véanse tablas 5 y 6 ).

Por último, se debe señalar que la modelación morfológica de tejidos urbanos aparece como un ámbito de renovado interés, no solo para la comprensión de los procesos de diseño paramétrico (en nuestro caso, de modelación de un espacio y un volumen textural) sino para la comprensión y abordaje estratégico de los procesos de crecimiento, autoconstrucción, subdivisión y densificación espontánea en ciudades vernaculares latinoamericanas como Valparaíso. cierto punto esto se ve reforzado por una valoración 


\section{TABLA 5. Evolución de la exploración morfológica en la arquitectura moderna}

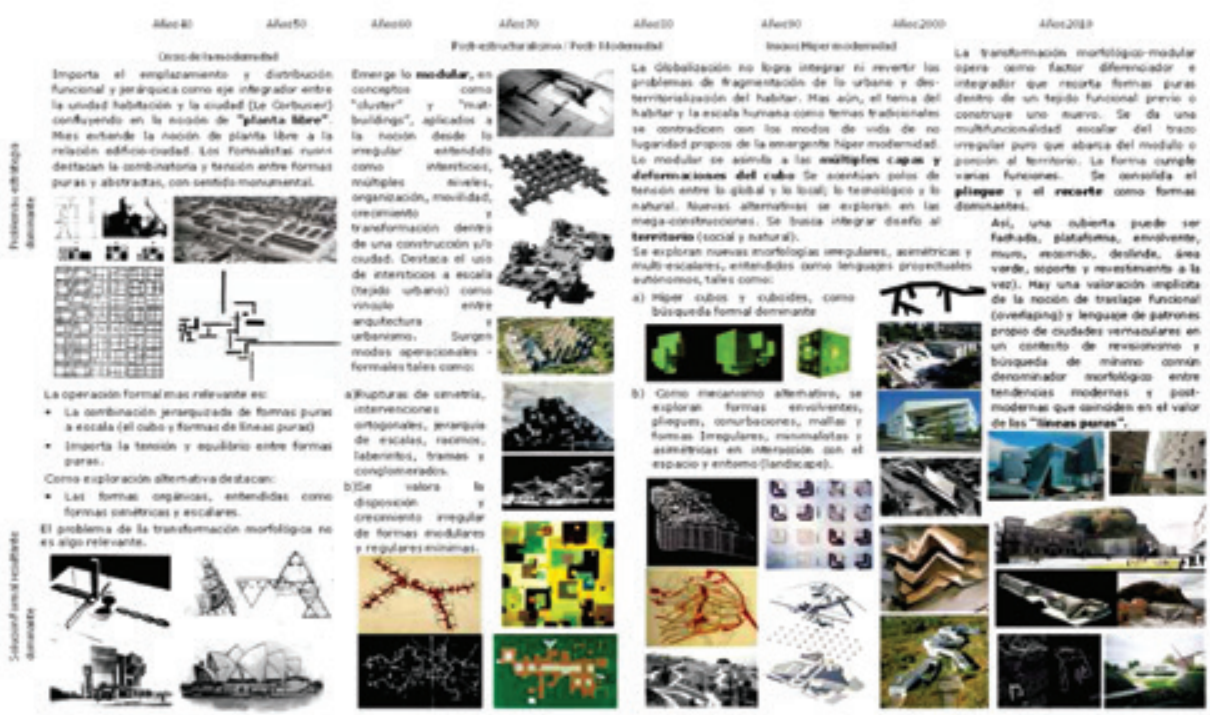

Fuente: Elaboración propia.

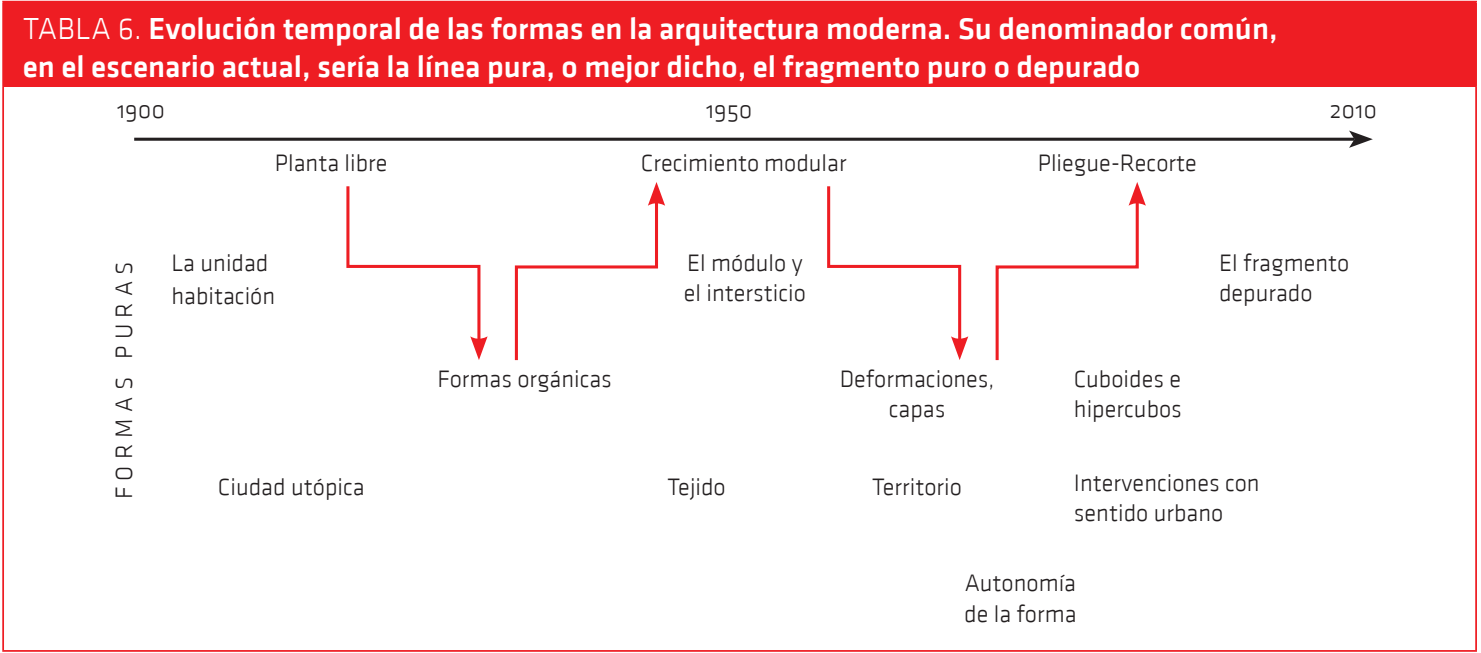

Fuente: Elaboración propia. 


\section{ANTECEDENTES}

\author{
Modelación de tramas. Revisión \\ de la propia experiencia
}

¿O cómo habré de trazar de la manera más libre el puente entre lo interior y lo exterior?

Paul Klee, en Diarios. 18g8-1917.

Como se ha señalado, la presente propuesta se basa en el estudio de procesos de crecimiento y fragmentación modular, y como estos inciden en la formación de morfologías complejas, como las tramas, la textura, las gradientes entre escalas, delimitación y compactación mutua de texturas modulares, co-actuando en la generación de paisajes digitales, poniendo énfasis en el uso de líneas irregulares puras.

Inicialmente hemos de destacar, entonces, la conformación de ciertas tramas y gradientes paisajísticas morfológicas (véanse imágenes 12-16) que surgen de las primeras exploraciones (Cañete 2012: en Cañete et al. 2012). Este tipo de modelaciones morfológicas de texturas y tramas paisajísticas globales ha sido abordado en el marco del diseño y modelación paramétrica, y explorado por el autor en sucesivos proyectos de artes visuales financiados por FONDART (Fondo Nacional del Arte) 4 Regional de Artes Visuales (véanse Cañete y Bahamondes, 2011a y 2011b; Cañete, Bahamondes y López, 2012). También se ha desarrollado como parte de

4. FONDART es una agencia gubernamental que tiene como fin apoyar iniciativas de creación artística. Destaca el ámbito de artes visuales, donde el presente autor ganó y ejecuta proyectos en 2011, 2012 y 2015, en morfologías digitales, publicándose libros de los cuales fue editor y coautor. los encargos propios del ramo de Fractales y del módulo de forma, en el Taller de Ciudad, en tercer y segundo año de la carrera de arquitectura de la Universidad de Valparaíso, respectivamente. Sin embargo, complementariamente a la formación de texturas paisajísticas resultó interesante, además, explorar el proceso de transformación morfológica como lenguaje generativo (llevado al plano de la fragmentación y ensamble modular) y sus posibilidades en tanto metodología de exploración de intersticios, volúmenes, ensambles y relaciones entre módulos que la textura sugiere. Dichas modelaciones fueron desarrolladas en diversos programas y softwares, destacando Grasshoper, Sketchup y Corel-Draw.

También se pone énfasis en una profundización en algunos principios específicos propios de la expresión estética y exploración morfológica contemporánea:

Una aproximación minimalista. Se apela al uso de líneas puras -mediante el uso de mecanismos de vectorización- como medio de optimización y depuración del trazo. Desde el punto de vista compositivo solo hay líneas y nodos que se conurban, delimitan e interactúan entre sí.

Un enfoque modular, basado en la modelación de procesos de crecimiento y fragmentación morfológica. Una combinación de ambos procesos de transformación otorga una mayor ductilidad y posibilidades de generación de morfologías, y especialmente de tramas, a explorar.

El estudio y modelación de tramas, paisajes y landscapes. Apelando a los principios anteriores, el conjunto resultante de procesos de integración y desintegración 


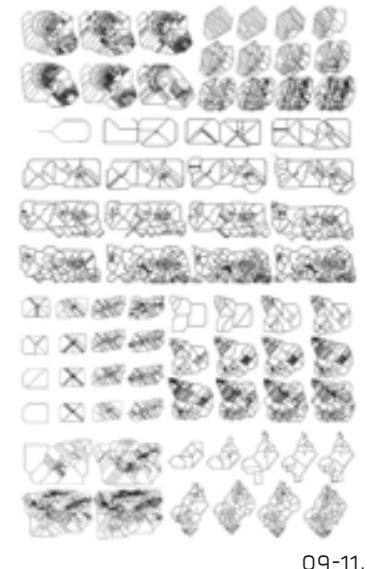

compositiva es una fuente generadora de paisajes y totalidades mayores.

Estos principios han de explorarse siguiendo los siguientes criterios y mecanismos orientados a explorar principios morfológico-arquitecturales:

Delimitación de módulos y formación de ensambles y encajes modulares. Lo anterior permite un estudio volumétrico de las unidades estructurales y ensambles modulares asociado al proceso de contacto y deslinde entre unidades, y cómo se afectan morfológicamente al entrar en contacto y ensamble con otras unidades, y estas con el resto del conjunto de unidades modulares. Un ejemplo de esto es la búsqueda de conformación de plataformas entre unidades y módulos a distintas alturas, encajes, pliegues entre capas, etcétera.

La formación de pasajes, pasillos, vacíos, intersticios y circulaciones entre módulos y sus uniones. El ensamble de módulos permite regular la distancia entre estos, así como la posibilidad de crear circulaciones dentro y entre los módulos, también dentro del conjunto de la textura volumétrica y sus intersticios existentes en el paisaje global.

Formación volumétrica de texturas y gradientes escalares. Con base en los procesos de interacción, compactación, fragmentación y/o crecimiento modular se
09-11.

Estudios de formación de gradientes vectorizadas basadas en procesos de fragmentación y crecimiento modular.

IMAGEN DEL AUTOR

generan diferenciaciones escalares de los módulos interactuando entre sí, lo que incide en la formación de gradientes y texturas morfológicas.

\section{Diseño paramétrico y modelación de texturas}

Dichas modelaciones fueron desarrolladas en diversos programas y softwares, destacando Grasshoper, Sketch-up y Corel-Draw. Por cierto, cada uno de estos ámbitos es un campo propio de estudio y modelación, pero que puede encontrar recíprocas áreas de confluencia y exploración morfo-estética, como en la presente búsqueda, que se describe.

\section{Bases de un proyecto de estudio}

Desde el punto de vista de la modelación que se buscó desarrollar en el encargo resulta importante la distinción entre: a) un sentido pre-proyectual y, b) un sentido morfológico-estético. En ambos tipos de exploración que los alumnos asumieron, buscando que aclararan el sentido para cada uno de los casos, resulta más comprensible evaluar las estrategias que guiaran las operaciones propiamente tales para cada caso. Así, se puso énfasis en que estos niveles aparecen en cualquier tipo de modelación, y que en cierto sentido son partes de un proceso exploratorio global continuo 
12-15

Exploración modular

de transformaciones vectoriales.

IMAGEN DEL AUTOR
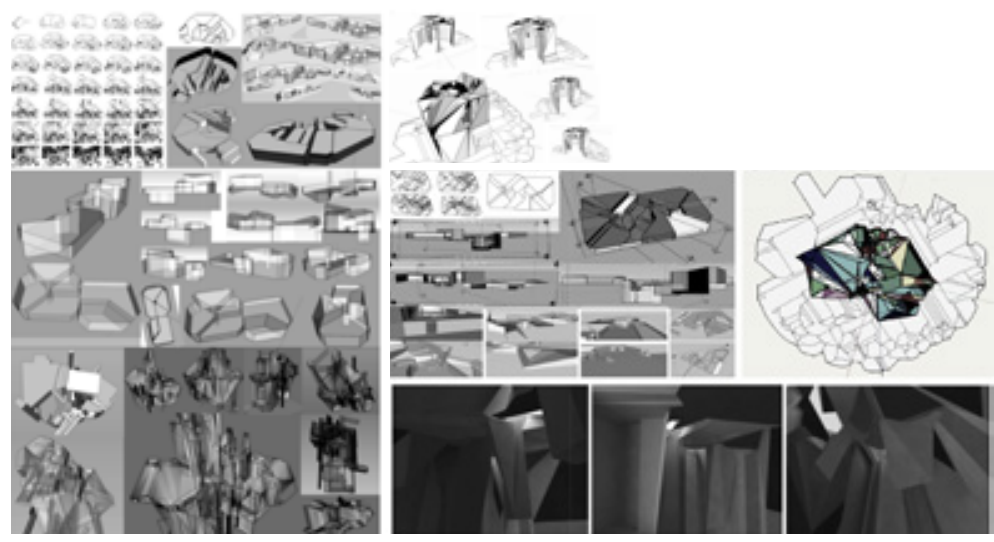

$12-15$ que deben articular, pero que cada uno permite a su vez un amplio campo de indagación específica. Se les presentaron los siguientes casos, a modo de ejemplo, intencionando distintas posibilidades y niveles de exploración.

En el caso de las imágenes 16-20, a partir de exploraciones más actuales, además se estudia el desarrollo de vistas y recorridos interiores con base en la incidencia de aberturas de luz y colores, en tramas extruidas, que apelan al prisma o al cristal como imagen metafórica estructurante.

\section{METODOLOGIAA}

\section{Bases del encargo}

Por último, se les pide realizar una maqueta, sea con alambres, cartón-cartulina, plumavit o técnica mixta, en un espacio no mayor a un cubo de $60 \mathrm{~cm}^{3}$. Así, el encargo constó de dos tipos de exploración y trabajo ordenados progresivamente:

- Exploración morfológica generadora de gradientes.

- Exploración volumétrica de estructuras modulares a partir de la textura.

\section{RESULTADOS}

La forma actual de este problema puede definirse asi en lo sucesivo: la intuición y la lógica, ¿participan de un modo igualmente legítimo en la creación de la obra? [...] Por consiguiente, todos los medios son buenos para esta materialización necesaria, la lógica tanto como la intuición.

Kandinsky, W., en La gramática de la creación. El futuro de la pintura.

Como se ha señalado, el enfoque minimalista de la modelación de texturas y paisajes nos ha permitido abrir las siguientes áreas de exploración:

\section{Delimitación de módulos, y formación de ensambles} y encajes modulares. Hemos de destacar dos subcampos:

\section{Estudio volumétrico de las unidades modulares y ensambles asociados.}

Véanse los siguientes casos:

En el primer caso estudiado se exploraron leves extrusiones, destacando pequeñas franjas concéntricas, las cuales permitían articular pequeños pasadizos, muros, recorridos y circulaciones entre plataformas. 

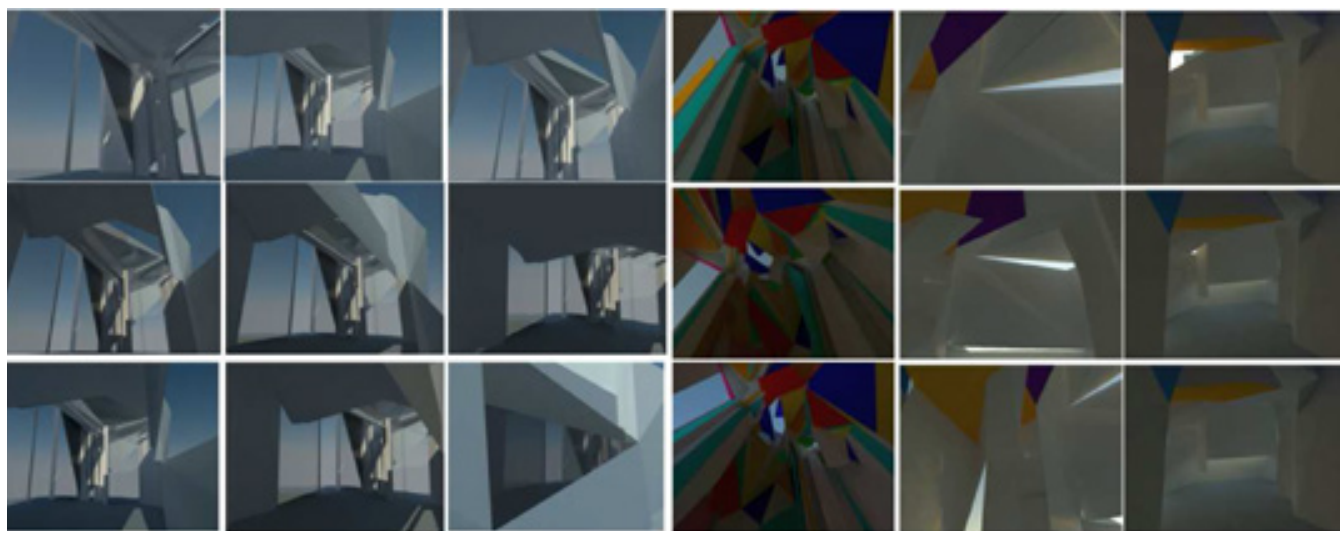

$16-20$.

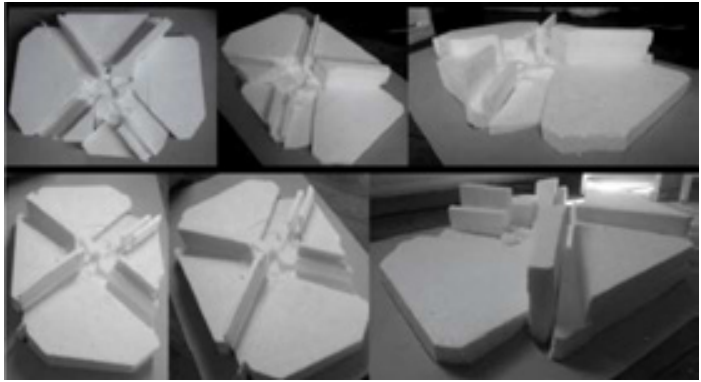

21.

Valentina Guzmán y Emiliano Manfred exploraron la extrusión pero de un modo leve, ajustando un pequeño levantamiento volumétrico.

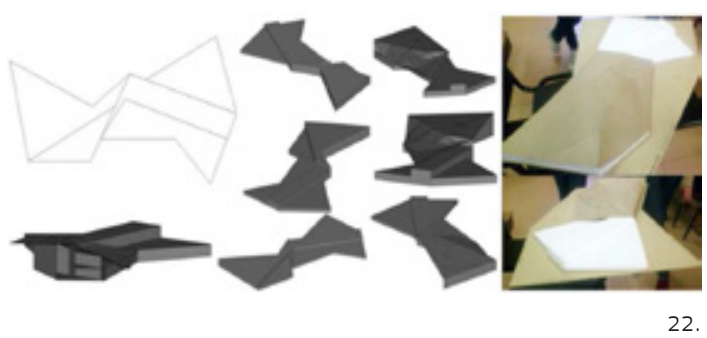

Hemos de incluir las modelaciones de Catalina Farías, que incluye una compleja red de vistas interiores que sugieren circulaciones y contrastes entre alturas y plataformas:

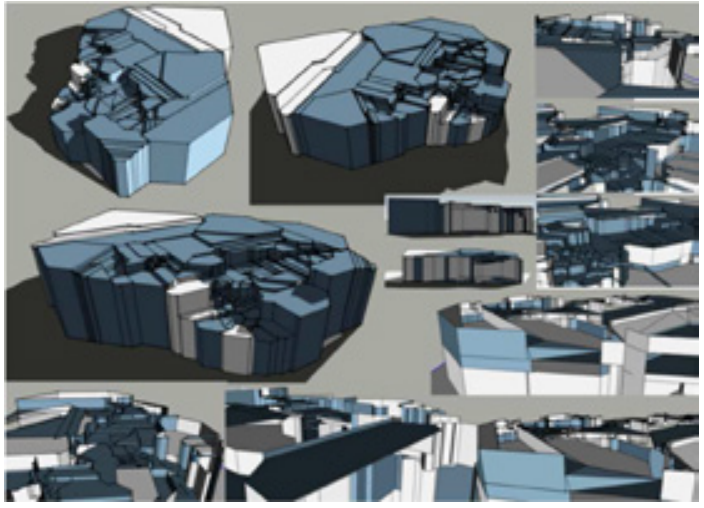

Estudio del contacto y deslinde entre unidades y módulos.

Véanse los siguientes casos:

Destaca primero la exploración de anillos concéntricos que se ensamblan modularmente, formando diversas plataformas que articulan un recorrido. También presentan un estudio de cortes y secciones.

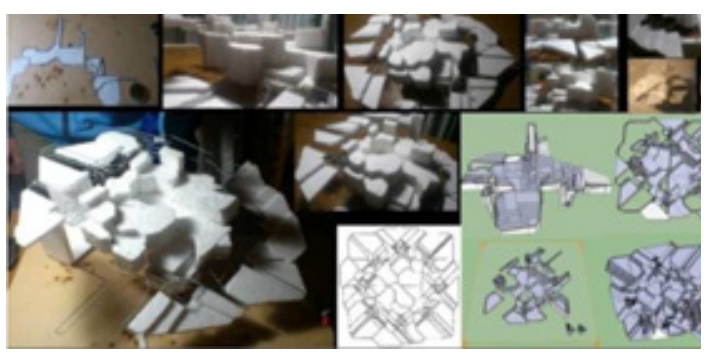


$16-20$.

Recorridos y vistas interiores de una trama volumétrica cristalizada. Desde su interior se exploran en rander las vistas de su recorrido (2015).

IMAGEN DEL AUTOR

21 y 22

Encargo ramo Geometría Fractal, año 2013.

23.

Encargo ramo Geometría Fractal, año 2014

24,25 y 26

Encargo ramo Geometría Fractal, año 2013

Similar situación ocurre en el siguiente caso, pero en una trama distinta, donde se trabajaron ciertos módulos sugeridos por la trama, los que son posteriormente ensamblados a una malla de alambre que regula sus interrelaciones:

La formación de vacíos, espacios, pasajes, pasillos, intersticios y circulaciones entre módulos y sus ensambles. Véanse los siguientes casos:

En este otro caso las plataformas más bajas quedan ubicadas al centro, en torno a una diagonal que demarca los fragmentos más pequeños, siendo esta diagonal la que delimita una gradiente de escalas en pequeñas diferencias de alturas.

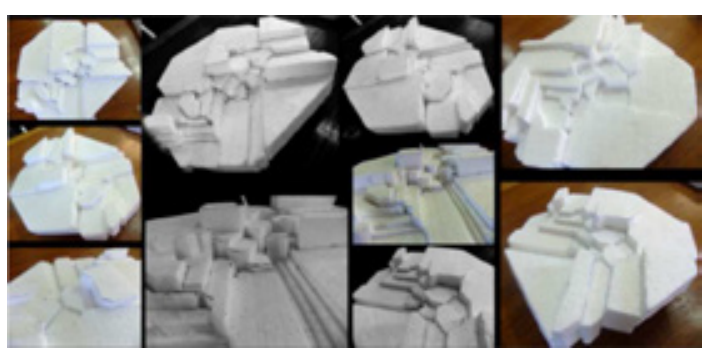

En el siguiente caso se exploró un pequeño vacío central en torno al cual se elevan los volúmenes concéntricamente, dejando un pasadizo de acceso y circulación en uno de sus lados.

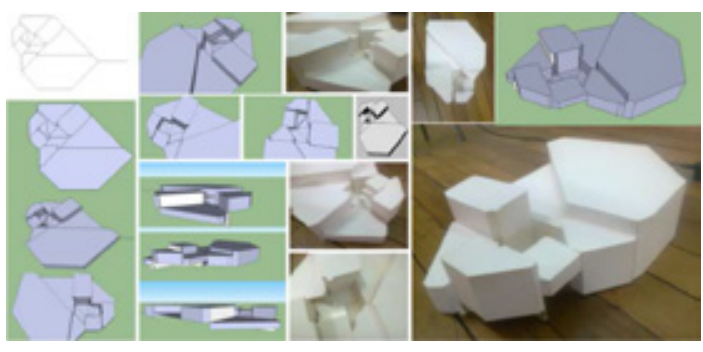

26.

Destaca el siguiente caso, donde primero se subdividió la trama en cuatro grandes zonas territoriales para luego extruir algunos segmentos desde sus deslindes y límites a modo de muros o paneles, en conjunto con algunas cubiertas, intencionando la formación de recorridos y circulaciones interiores e intersticios laberínticos abiertos y no cerrados. 
27, 28, 29 y 30

Encargo ramo Geometría Fractal, año 2014.

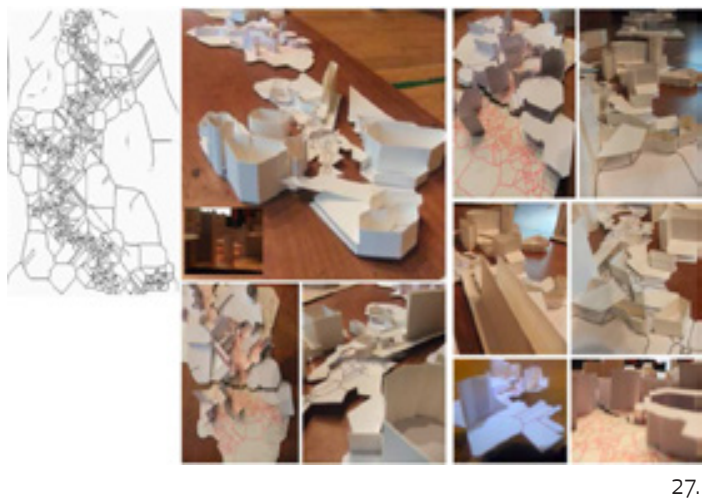

El siguiente caso logra articular la formación de vanos, como circulaciones envolventes en intersticios delimitados por plataformas y semivolúmenes, logrando la articulación entre los módulos sugeridos por la forma general.

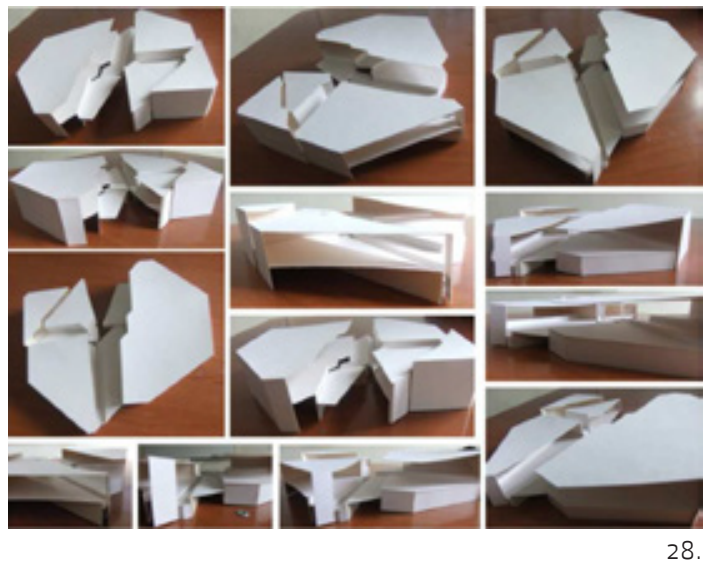

El siguiente caso explora sutiles cortes, a modo de incisiones demarcadas mediante fisuras que delimitan y sugieren la existencia de vanos interiores además de circulaciones y, entre semienvolventes, plataformas y vanos internos del conjunto.
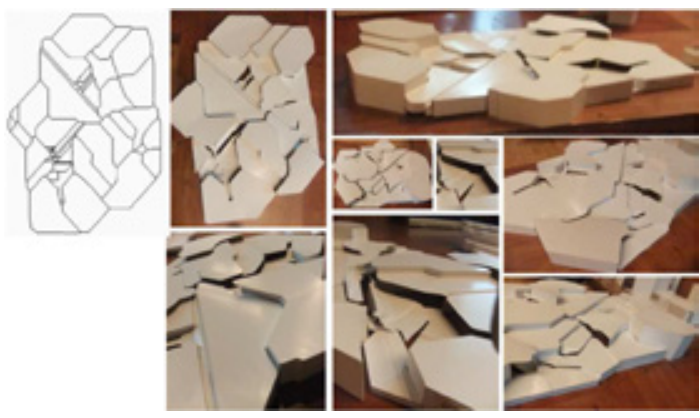

29

Por último, el siguiente caso estudia con base en unos cortes aplicados a la trama original, en sucesivos dobleces, a modo de origami, elaborando una trama de paneles semivolumétricos.
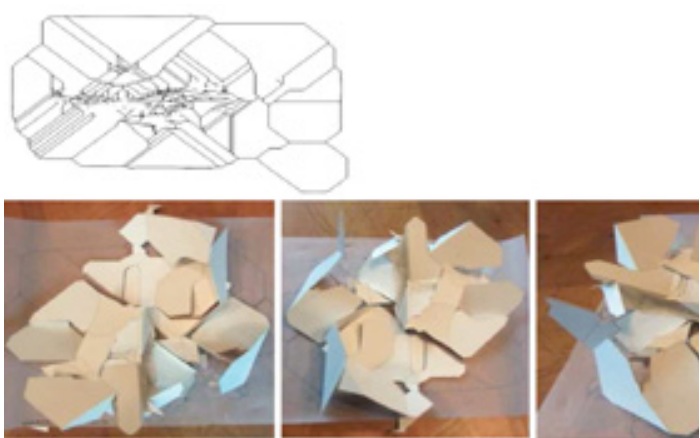

30. 


\section{CONCLUSIONES Y COMENTARIOS}

\section{FINALES}

\author{
He aqui el mar. \\ El mar abierto de par en par. \\ He aqui el mar quebrado de repente \\ para que el ojo vea el comienzo del mundo. \\ Vicente Huidobro, «Monumento al mar».
}

En la presente propuesta hay, por cierto, una búsqueda subyacente de ampliar la exploración hacia nuevos desarrollos morfológicos, en este caso orientada al estudio de tramas, en relación con los procesos de crecimiento y fragmentación escalar a su base generativa (y no solo un crecimiento con base en el ensamble de módulos de tamaños relativamente fijos).

Así, destaca en el actual trabajo el estudio de las gradientes generadas por el deslinde y delimitación mutua que generan la compresión e interacción modular y su incidencia en la formación de texturas, desde un punto de vista de los subprocesos de crecimiento y fragmentación que supone, aparece como una estrategia que, tomada desde una búsqueda de las unidades modulares texturales mínimas que permiten una exploración volumétrica interesante, de aún inexplorado desarrollo. Esto permite un aumento de posibilidades, con base en tramas depuradas vectorialmente, de exploración volumétrica espacial, sea a partir de operaciones de mera extrusión como de tantas otras de tipo operatorio-manual, permitiendo ampliar las posibilidades de exploración, incluso de una misma trama de base. Esta trama permite y fomenta, también, operaciones en diversos momentos de expresión.

La trama minimalista, al ser tratada, desde su modelación, como una unidad orgánica, ofrece una capacidad para albergar distintas y diversas exploraciones morfológico-espaciales.

Finalmente, desde el punto de vista arquitectónico, dicha exploración morfológica orientada a la búsqueda de operaciones como la formación y delimitación de vacíos, la organización de ensambles, el uso de diversas extrusiones y operaciones volumétricas, la conformación de plataformas y alturas, uso de recorridos e intersticios, etcétera, permite nuevas exploraciones orgánicas, con sentido no solo estético-morfológico, sino, en muchos casos, de relevancia pre-proyectual..

RECIBIDO: 25 de septiembre de 2014 ACEPTADO: 2 de diciembre de 2014 


\section{REFERENCIAS}

\section{Libros}

ALBERS, J. (2010). Selected Works. Ed. Taschen.

ALEXANDER, C. (1979). Lenguaje de patrones. Ed. GG.

- (1971). The City is not a Tree. Ed. GG.

ARNHEIM, R. (2000). El quiebre y la estructura. Ed. Andrés Bello.

BORJA-VILLEL, M. et al. (2005). Campos de fuerza. Ed. Macba. Barcelona. España.

CABANE, P. (1967). Conversaciones con Marcel Duchamp. Ed. Anagrama. Barcelona.

CAÑETE, O. (2014). Arquitectura, complejidad y morfogénesis. Ed. Universidad de Valparaíso.

- (Coord.), Bahamondes, C. \& F. M. López, (2012). Exploraciones morfológicas digitales. Ed. Fondart/Garin.

- (Coord.), Bahamondes, C. (2011a). Computación y arte computacional gráfico. Ed. Fondart/Garin.

CARRASCO, E. (2011). Conversaciones con Matta. Ed. Universidad Diego Portales.

DELEUZE, G. (1985). La imagen-movimiento. Estudios sobre cine.

- (1987). La imagen-tiempo. Estudios sobre cine. Ed. Paidós.

- (1989). El pliegue. Ed. Paidós.

- (2000). Mil mesetas. Ed. Pre-Textos.

- (1971). Lógica de sentido. Ed. Seix-Barral. Barcelona.

DALÍ, S. (1971), El mito trágico del Angelus de Millet. Ed. Espasa Calpe. Madrid.

- (2003). Dalí. Ed. Espasa Calpe. Madrid.

FEDERL, P. (2002), «Modeling Fracture Formation on Growing Surfaces». University of Calgary. A thesis submitted to the faculty of graduate studies in partial fulfilment of the requirements for the degree of doctor of philosophy. En: The University of Calgary.

- (2002), «Modeling Fracture Formation on Growing Surfaces». Thesis submitted to the Faculty of Graduated studies in partial, fulfillment of the requirements for the degree of doctor of philosophy, at University of Calgary. Canada.
FUHRER, M. (2005), «Hairs, textures, and shades: improving the realism of plant models generated with I-systems». A thesis submitted to the faculty of graduate studies in partial fulfillment of the requirements for the degree of master of science department of computer science. Calgary, Alberta.

CROHMANN, W. (1984). Paul Klee. Harry N. Abrams; Inc. Publisher. New York.

KANDINSKY, W. (1979a). Mirada retrospectiva. Ed. Emecé.

- (1979b). Acerca de lo espiritual en el arte. Ed. La Nave de los Locos.

- (1993). Punto y línea sobre el plano. Ed. Labor.

- (1994). La gramática de la creación. El futuro de la pintura. Ed. Paidós.

KLEE, P. (1971). Teoría del arte moderno. Ed. Caldén. Colección El Hombre y su Mundo.

- (1979). Diarios. 1898-1917. Ed. Caldén.

LANE, B. (2002), «Models of plant communities for image synthesis». A thesis submitted to the faculty of graduate studies in partial fulfillment of the requirements for the degree of master of science department of computer science. Calgary, Alberta.

MANDELBROT, B. (1989). Los objetos fractales. Ed. Tusquetes.

MOHOLY-NAGY, L. (1972). La nueva visión y reseña de un artista. Ed. Infinito.

LINDENMAYER, A. \& P. PRUSINKIEWICZ (2000). The Algorithmic Beauty of Plants. Ed. Spriger-Verlag.

LEAVITT, R. (editor). (1976). Artist and Computer. Ed. Harmony Books, New York.

MATISSE, H. (1990). Escritos y opiniones sobre el arte. Ed. Alianza.

OYARZÚN, P. (2000). Anestética del Ready-made. Ed. Lom.

PAZ, O. (1974). La búsqueda del comienzo. Escritos sobre el surrealismo. Ed. Fundamentos.

PLINIO el Viejo (1987). Textos de historia del arte. Ed. Visor.

ROZIN, D. (2010). An overview of artworks of Daniel Rozin. Ed. Bitforms Gallery. 
SHUMACHER, P. (2008). The Autopoiesys of Architecture. Ed. GG.

ZUBIRI, X. (1990). Estructura dinámica de la realidad. Ed. Alianza.

- (2005). Inteligencia y razón. Ed. Alianza.

- (2006). El problema filosófico de la historia de las religiones. Ed. Alianza.

\section{Capítulos de libro}

CAÑETE ISLAS, O. (2012). «Composiciones morfológicas», en Cañete, Omar (coord.), Bahamondes, Catalina \& López, Felipe Mateo (2012). Exploraciones morfológicas digitales. Ed. Fondart/Garin.

LÓPEZ, F. M. (2012). «Paisajes, mapas y atracción. Notas para el uso de algoritmos y patrones en el diseño paramétrico, desde el pensamiento arquitectónico y proyectualestético», en Cañete, Omar (coord.), C. Bahamondes, \& F. M. López (2012). Exploraciones morfológicas digitales. Ed. Fondart/Garin

WINNICOT, D. (1959), «El destino del objeto transocional», en Obras completas. Ed. Psikolibro.

ZUBIRI, X. (1980). «Inteligencia y realidad», en Inteligencia sentiente. Alianza Editorial, Madrid.

\section{Publicaciones seriadas}

CAÑETE, O. (coord.); BAHAMONDES, C. (2011a). «Experiencia y experimentación de morfologías digitales. Modos de pensamiento y alcances para una reflexión sobre lo inmaterial y esencial en arquitectura», en revista Márgenes, de la Facultad de Arquitectura, Universidad de Valparaíso, año 2011, vol. 8-9, pp. 50-62.

\section{Artículos en páginas de Internet}

Atari Archives (2011). Recuperado en: http://www. atariarchives.org/artist/

DELANDA. Centro Nacional de Arte, website page (2011). Recuperado en: http://cmm.cenart.gob.mx/delanda/ index.html

DRAVES, S. \& E. RECKASE (2008), «The Fractal Flame Algorithm». Recuperado en: http://flam3.com/flame.pdf

DIETRICH, F. (2000). «Visual Intelligence: The first decade of Computer Art (1956-1975)». Recuperado en: http:// beausievers.com/bhqfu/computer_art/readings/dietrichvisual_intelligence.pdf

GILOTH, C.; POCOCK-WILLIAMS, L. (2004). «Selected Chronology of computer Art. Exhibitions, Publication, and Technology». Recuperado en: https://www.iim.cz/wiki/images/d/dd/A-SelectedChronology-of-Computer-Art.pdf

LAMBERT, N. (2003). «A Critical Examination of "Computer Art: its history and application"». Recuperado en http://computer-arts-society.com/static/cas/ computerartsthesis/

Landscape Ecology Review of Calgary University, Canada (2011). Recuperado en: http://Landscape.Forest.Wisc. Edu/Landscapeecology/

FRAGSTATS (2010), «Programa de análisis espacial de patrones de mapas categóricos». Recuperado en: http://www.umass.edu/landeco/research/fragstats/ documents/fragstats_documents.html

OYARZÚN, P. (2012), «Indicio histórico sobre la relación de arte y ciencia». Recuperado en: http://psicologiadelarte. com/2012/06/“indicio-historico-sobre-la-relacion-dearte-y-ciencia"---colaboracion-pablo-oyarzun-robles/

PEIRCE, C. S. (2010), «C. S. Peirce en español». Disponible en: http://www.unav.es/gep/Peirce-esp.html. Visitado en febrero de 2010.

POTSCHIN, M. (2007), en Aile-Bulletin. International Association for Landscape Ecology. Recuperado en: www. wsl.ch/land/iale/bulletin.php

RAMÍREZ CAMARERO, G. y VIDAL CALVET, Miguel (2012), «Introducción al diseño generativo con grasshopper». Recuperado en: www.frikearq.com 
STENTIFORD, F. M. (1982). «Recent Works», en Page49, Computer Art Society Ouarterly. Recuperado en: http://www.bbk.ac.uk/hosted/cache/archive/PAGE/ PAGE49\%20Autumn\%201981.pdf

SHUMACHER, P. (2011), «Parametric as Style-ParametricistManifiesto». Recuperado en: http://www. patrikschumacher.com/Texts/Parametricism as Style. htm

WEEGHEL, «Kineticart» (2010). Disponible en: http://www. willemvanweeghel.nl/en/

WITHNEY, J. (1971), «Matrix I». Recuperado en: https://www. youtube.com/watch?v=PEn-IkXBVCs

YOUNGBLOOD, G. (1970). Expanded Cinema. Ed. P. Dutton \& Co., Inc., New York. Recuperado en: http://www.vasulka.org/ Kitchen/PDF_ExpandedCinema/ExpandedCinema.html

\section{Fuentes de imágenes}

05-08 Cañete 2012; en Cañete et al. 2012.

09-11 Cañete 2012; en Cañete, Bahamondes y López, 2012. 